\title{
ALDH1A1 is a marker for malignant prostate stem cells and predictor of prostate cancer patients' outcome
}

\author{
Ting $\mathrm{Li}^{1,4}$, Yun Su${ }^{2,4}$, Yuping Mei ${ }^{1}$, Qixin Leng ${ }^{1}$, Bingjie Leng ${ }^{1}$, Zhenqiu Liu ${ }^{3}$, Sanford A Stass ${ }^{1}$ and Feng Jiang
}

Prostate cancer (PCa) contains a small population of cancer stem cells (CSCs) that contribute to its initiation and progression. The development of specific markers for identification of the CSCs may lead to new diagnostic strategies of PCa. Increased aldehyde dehydrogenase $1 \mathrm{~A} 1$ (ALDH1A1) activity has been found in the stem cell populations of leukemia and some solid tumors. The aim of the study was to investigate the stem-cell-related function and clinical significance of the ALDH1A1 in human PCa. ALDEFLUOR assay was used to isolate ALDH1A $1^{+}$cells from PCa cell lines. Stem cell characteristics of the $\mathrm{ALDH} 1 \mathrm{~A} 1^{+}$cells were then investigated by in vitro and in vivo approaches. The ALDH1A1 expression was also analyzed by immunohistochemistry in 18 normal prostate and 163 PCa tissues. The ALDH1A1 ${ }^{+}$PCa cells showed high clonogenic and tumorigenic capacities, and serially reinitiated transplantable tumors that resembled histopathologic characteristics and heterogeneity of the parental PCa cells in mice. Immunohistochemical analysis of human prostate tissues showed that $\mathrm{ALDH} 1 \mathrm{~A} 1^{+}$cells were sparse and limited to the basal component in normal prostates. However, in tumor specimens, increased ALDH1A1 immunopositivity was found not only in secretory type cancer epithelial cells but also in neuroendocrine tumor populations. Furthermore, the high ALDH1A1 expression in PCa was positively correlated with Gleason score $(P=0.01)$ and pathologic stage $(P=0.01)$, and inversely associated with overall survival and cancer-specific survival of the patients $(P=0.00093$ and 0.00017 , respectively). ALDH1A1 could be a prostate CSC-related marker. Measuring its expression might provide a potential approach to study tumorigenesis of PCa and predict outcome of the disease.

Laboratory Investigation (2010) 90, 234-244; doi:10.1038/labinvest.2009.127; published online 14 December 2009

KEYWORDS: ALDH1A1; biomarkers; cancer stem cell; prostate cancer; prognosis

Prostate cancer (PCa) is the most frequently diagnosed tumor and the second largest cancer contributing to mortality in men. Its treatment depend on the stage of the disease, resulting in variable clinical outcomes. ${ }^{1}$ Prognostic markers that can identify aggressive PCa and help select appropriate therapy to finally reduce the mortality are therefore urgently needed. However, current techniques are not accurate enough to predict the outcome of PCa. New diagnostic modalities have to be developed. ${ }^{1}$

The cancer stem cell (CSC) model proposes that tumorigenesis is driven by CSCs that might be derived from mutated adult stem cells (SCs). CSCs are functionally defined by the following criteria: high tumorigenicity, self-renewal capacity, and recapitulating the heterogeneity of the original primary tumor. ${ }^{2}$ Although being present in small numbers in tumor tissues, CSCs are believed to be responsible for progression and relapse of cancer. ${ }^{3}$ Therefore, CSCs could provide a prognostic strategy for human malignancies. For example, CD133, a commonly used marker to characterize colon CSCs, was proven to be an independent prognostic factor that correlated with low survival of colon cancer patients. ${ }^{4}$ Accumulating evidence posit that CSC concept is also relevant to $\mathrm{PCa} .{ }^{5}$ The growth and metastasis of PCa might be promoted by CSCs that are responsible for its aggressiveness and frequently recur after therapy. ${ }^{6}$ Therefore, identification of specific markers for the CSCs would enhance our understanding of the tumor biology of prostate. More importantly, these specific markers could be developed as a new diagnostic system for monitoring the progression of $\mathrm{PCa}$ and offering the best opportunity to prevent its recurrence, and hence probably cure the challenging malignancy.

\footnotetext{
'Department of Pathology, University of Maryland School of Medicine, Baltimore, Maryland, USA; ${ }^{2}$ Department of Surgery, Zhongda Hospital, The School of Clinical Medicine, Southeast University, Nanjing, China and ${ }^{3}$ Division of Biostatistics, The University of Maryland Greenebaum Cancer Center, University of Maryland School of Medicine, Baltimore, Maryland, USA

Correspondence: Dr F Jiang, MD, PhD, Department of Pathology, The University of Maryland School of Medicine, 10 South Pine Street, MSTF 7th floor, Baltimore, MD 21201-1192, USA.

E-mail: fjiang@som.umaryland.edu

${ }^{4}$ These authors contributed equally to this work.

Received 24 July 2009; revised 4 September 2009; accepted 16 September 2009
} 
Human mature prostatic glands consist of basal, secretory luminal, and neuroendocrine cells. Prostate CSs are suggested to localize in the basal cell layer. Several candidate populations of prostate stem/progenitors cells have been reported, including those expressing cell surface markers, CD44, $\alpha 2 \beta 1$, or CD133. ${ }^{7,8}$ For example, Collins et al found that the $\alpha 2 \beta 1^{+}$cells comprised $\sim 15 \%$ of $\mathrm{CD} 44^{+}$basal cells and possessed high colony-forming efficiency and an ability to generate prostate-like acini when engrafted in nude mice. ${ }^{7}$ As CSCs share properties with normal SCs, CSCs of PCa have been isolated using these cell surface markers. ${ }^{5}$ However, $\mathrm{PCa}$ cells that highly express the markers do not always appear to tightly mark a cell population with the CSC characteristics. ${ }^{5}$ In particular, the ability of these cells to successively reinitiate transplantable tumors remains uncertain, while serial xenotransplantation is regarded as the gold standard for proving the existence of CSCs. ${ }^{9,10}$ Moreover, clinical significance of the surface markers, especially relevance for PCa patients' outcome is not clear.

Aldehyde dehydrogenase (ALDH) is an enzyme involved in intracellular retinoic acid production. ${ }^{11}$ ALDH1A is an important member of the ALDH family that includes 17 genes encoding different substrate specificities, of which ALDH1A1 catalyzes the oxidation of retinal to retinoic acid. ${ }^{11}$ Retinoic acid signaling is linked to cellular differentiation during development and has important function in SC self-protection throughout an organism's lifespan. ${ }^{12-15}$ Activation of ALDH1A1 has been found in the SC populations of multiple myeloma and acute myeloid leukemia. ${ }^{16}$ Ginestier et $a l^{17}$ showed that ALDH1A1 was a marker of normal and malignant human mammary SCs and a predictor of poor clinical outcome of breast cancer patients. We recently showed that the ALDH1A1 ${ }^{+}$lung cancer cells could generate tumors that resembled the heterogeneity of the parental cancer cells. ${ }^{18}$ Furthermore, elevated ALDH1A1 expression was correlated with the stage and grade of lung tumors and associated with a poor prognosis for the lung cancer patients. ${ }^{18}$ In addition, high ALDH activity was recently proven to be a novel functional marker of murine prostate SCs. ${ }^{19}$ However, no research has been reported regarding the role of ALDH1A1 in tumorigenesis of human prostate and its clinical importance in the disease.

In this study, we first used ALDEFLUOR assay and fluorescence-activated cell sorting (FACS) to isolate ALDH1A1 ${ }^{+}$ cells from human PCa cell lines. The ALDH1A1 ${ }^{+}$cancer cells showed important CSC properties: high in vitro tumorigenicity, in vivo tumor initiation and self-renewal capacities, and successively reinitiating transplantable tumors that gave rise to a heterogeneous population of cancer cells. Moreover, immunohistochemistry analysis of clinical specimens showed that $\mathrm{ALDH} 1 \mathrm{Al}^{+}{ }^{+}$cells were sparse and resided in the basal layers of normal prostate glands. However, in cancer specimens, ALDH1A1 immunopositivity was found not only within secretory type cancer epithelia but also among neuroendocrine tumor cells. High ALDH1A1 expression corre- lated significantly with the patient's poor survival. ALDH1A1 could therefore be a prostate CSC-associated marker, and might provide a potential prognostic factor for the malignant progression of PCa.

\section{MATERIALS AND METHODS Cell Lines and Cultures}

PCa cell lines, PC 3 cells, and LNCaP cells were obtained from the American Type Culture Collection (ATCC, Manassas, VA, USA). The cells were maintained in the culture medium recommended by ATCC and harvested when they were in the logarithmic phase of growth for use in the following experiments.

\section{Isolation of ALDH1A1 ${ }^{+}$Cell Population by ALDEFLUOR Assay and FACS}

An ALDEFLUOR kit (StemCell Technologies, Durham, NC, USA) optimized for interaction with human ALDH1A1 was used to identify ALDH1A1 ${ }^{+}$cells as previously described. ${ }^{18}$ Briefly, the brightly fluorescent ALDH1A1-expressing cells were detected using an Aria cell sorter (BD Biosciences, San Jose, CA, USA). Side-scatter and forward-scatter profiles were used to reduce cell doublets. Nonviable cells were eliminated using the viability dye $4^{\prime}, 6$-diamidino-2-phenylindole (Sigma, St Louis, MO, USA). Specific ALDH1A1 activity was based on the difference between the presence/ absence of the ALDEFLUOR inhibitor diethylaminobenzaldehyde (DEAB) (Sigma). Data were analyzed using Cell Quest software (BD Biosciences). Each experiment was repeated three times.

\section{Clonal Analysis and Clonogenic Assays}

Cells were plated at a density of 200 per well in a six-well tissue culture dish, as described in our previous report. ${ }^{18}$ Clones with $>50$ cells were scored at the end of week 2 . The percentage of cells that initiated a clone was presented as cloning efficiency. For clonogenic assays, cells were plated at 1000 per well in six-well culture dishes coated with a thin layer of $1 \%$ solidified agar. ${ }^{9,18}$ The appearance of spheres within 3 weeks was considered as clonogenicity. For each cell type, triplicate samples were performed and clones or spheres were counted in a blind manner by two individuals.

\section{Xenografting}

Cells were resuspended in serum replacement medium at 1000 cells per $50 \mathrm{ml}$ and mixed with an equal volume of Matrigel (BD Biosciences). The cells were then implanted into the dorsal prostate of $10 \mathrm{NOD} / \mathrm{SCID}$ mice, which has been widely used as an 'orthotopic' implantation site for human PCa. ${ }^{9}$ Tumorigenicity was measured mainly by tumor incidence (ie, the number of tumors/the number of injections), size of tumor, and latency (ie, time from injection to detection of palpable tumors). The mice were observed for 6 weeks to allow tumor growth and then killed under deep anesthesia with pentobarbital (Sigma). Tumor volume $\left(\mathrm{mm}^{3}\right)$ 
was calculated as $\left(W^{2} \times L\right) / 2$. A part of each engrafted tumor tissue was dissociated with collagenase IV (Sigma) and incubated with mechanical disruption as previously described. ${ }^{18}$ Serial transplantations of the PCa xenografts were performed by regrafting the freshly disassociated cells into male mice. The disassociated cells were also reanalyzed by using ALDEFLUOR assay for FACS analysis, as described above. Immunofluorescence study was undertaken on the cells from the engrafted tumors to evaluate expressions of ALDH1A1, CD44, and androgen receptor (AR) as described below. Moreover, a portion of each tumor tissue was fixed in $10 \%$ formaldehyde and embedded in paraffin for histopathologic study.

\section{Immunohistochemical and Immunofluorescence Analyses}

To explore expression patterns of ALDH1A1 in normal prostate and $\mathrm{PCa}$ tissues and their relationship with those of $\mathrm{CD} 44, \mathrm{AR}$, and chromogranin $\mathrm{A}$, we obtained tissue microarrays (TMAs) (US Biomax, Frederick, MD, USA) constructed from 18 normal prostate and $64 \mathrm{PCa}$ tissues (Table 1). Immunohistochemical (IHC) staining was carried out on the consecutive TMA sections using antibodies against ALDH1A1 (Santa Cruz Biotechnology, Santa Cruz, CA, USA), CD44 (eBioscience, San Diego, CA, USA), AR (Santa Cruz Biotechnology), and chromogranin A (Vector Laboratories, Burlingame, CA, USA), as previously described. ${ }^{20,21}$ Immunoreactive staining intensity for each antibody was rated according to the following scale: no visible staining $=0$, faint staining $=1$, moderate staining $=2$, and strong staining $=3$. The total number of cells with positive staining for the antibodies was quantitated on each tissue spot $\left(0.6 \mathrm{~mm}^{2}\right)$ of the TMAs. The percentage of cells with positive staining was graded as $0,<10,10-25,25-50$, and $\geqslant 50-75 \%$.

As the clinical follow-up information for the specimens on the TMAs was not available to evaluate the associations between ALDH1A1 expression and PCa patients' outcomes, we obtained formalin-fixed and paraffin-embedded PCa tissue sections with follow-up outcomes from the School of Clinical Medicine of Southeast University in China. The specimens were collected from $99 \mathrm{PCa}$ patients who underwent radical retropubic prostatectomy between 1991 and 2003. The patients also received androgen deprivation therapy. As radiation therapy was unavailable for many patients, analysis influence of radiation on the patients was not included in the study. The minimum available follow-up on all patients was $6.72(0.6-16.4)$ years. Overall survival was measured using the dates of death from any cause. Cancer-specific survival was calculated using the dates of death from PCa. The study was conducted under a protocol approved by the institutional review board for human subjects' research. Geographic characteristics of the patients, including age, histopathologic diagnosis, and the survivals, are shown in Table 2. IHC with ALDH1A1 antibody was carried out and staining intensity
Table 1 Immunohistochemical analysis of prostate cancer specimens for ALDH1A1 expression on TMAs constructed from 18 normal prostate and 64 PCa tissues ${ }^{a}$

\begin{tabular}{|c|c|c|c|}
\hline Characteristics & $\begin{array}{l}\text { No. of } \\
\text { tissues }\end{array}$ & $\begin{array}{l}\text { High ALDH1A1 } \\
\text { expression }^{\mathrm{b}}\end{array}$ & $P$-value ${ }^{c}$ \\
\hline All tissues & 82 & & \\
\hline Age (years) & & & 0.62 \\
\hline$\leq 65$ & 22 & 4 & \\
\hline$>65$ & 60 & 9 & \\
\hline \multicolumn{4}{|l|}{ Diagnosis } \\
\hline Normal & 18 & 0 & \\
\hline Prostate cancer & 64 & 13 & \\
\hline \multicolumn{4}{|l|}{ Pathologic stage } \\
\hline $\mathrm{pT}_{2}$ & 39 & 5 & 0.01 \\
\hline$\geq \mathrm{pT}_{3}$ & 25 & 8 & \\
\hline Gleason grade & & & 0.01 \\
\hline$\leq 7$ & 44 & 7 & \\
\hline $8-10$ & 20 & 6 & \\
\hline
\end{tabular}

$\mathrm{ALDH}$, aldehyde dehydrogenase $1 \mathrm{~A} 1 ; \mathrm{PCa}$, prostate cancer; TMA, tissue microarray.

a The TMAs constructed from 18 normal prostate and 64 PCa tissues were obtained from US Biomax (Frederick, MD, USA). The clinical information, including prostatectomy, radiation, androgen deprivation, and follow-up date, was not available.

${ }^{\mathrm{b}} \mathrm{A}$ specimen with more than $10 \%$ overall score of ALDH1A1 was defined as one with high ALDH1A1 expression.

${ }^{c}$ All $P$-values were determined by two-sided tests. $P$-values $\leq 0.05$ were considered statistically significant.

was rated as described above. The total number of cells with positive staining for the antibodies was quantitated in 20 fields in each paraffin tissue section.

To elucidate whether ALDH1A1 ${ }^{+} \mathrm{PCa}$ cells could generate engrafted tumors with heterogeneity in mice, we also examined expressions of ALDH1A1, CD44, and AR using immunofluorescence assay with the above primary antibodies on the disassociated cells from the xenografts. The cells were then stained with a fluorescently conjugated IgG (Abcam, Cambridge, MA, USA) and examined under a Leica microscope (Leica Microsystems, Buffalo, NY, USA), as previously described. ${ }^{18}$ Each batch of slides contained a positive control and a negative control.

\section{Statistical analysis}

The statistical software SPSS12.0 (SPSS, Chicago, IL, USA) was used to analyze the differences between ALDH1A1 ${ }^{+}$and $\mathrm{ALDH}_{1 \mathrm{~A} 1^{-}}$cells with unpaired or paired $t$-tests for statistical significance. Kaplan-Meier models were applied to generate life tables. Differences between groups were examined using the log-rank test. Univariate and multivariate Cox regression analyses were carried out using stepwise methods for the analysis of ALDH1A1 staining results, age, histopathologic 


\begin{tabular}{|c|c|c|c|}
\hline Characteristics & No. of patients & $\begin{array}{l}\text { High ALDH1A1 } \\
\text { expression }^{\mathrm{a}}\end{array}$ & $P$-value ${ }^{\mathrm{b}}$ \\
\hline All cases & 99 & 19 & \\
\hline Age (years) & & & 0.83 \\
\hline$\leq 65$ & 34 & 6 & \\
\hline$>65$ & 65 & 13 & \\
\hline Follow-up time (years) & $0.6-16.4$ & & \\
\hline Median follow-up (years) & 6.72 & & \\
\hline \multicolumn{4}{|l|}{ Pathologic stage } \\
\hline $\mathrm{pT}_{2}$ & 68 & 11 & 0.02 \\
\hline$\geq \mathrm{pT}_{3}$ & 31 & 8 & \\
\hline Gleason grade & & & 0.02 \\
\hline$\leq 7$ & 70 & 10 & \\
\hline $8-10$ & 29 & 9 & \\
\hline
\end{tabular}

ALDH, aldehyde dehydrogenase $1 \mathrm{~A} 1$.

${ }^{a} \mathrm{~A}$ specimen with more than $10 \%$ overall score of ALDH1A1 was defined as one with high ALDH1A1 expression.

${ }^{\mathrm{b}}$ All $P$-values were determined by two-sided tests. $P$-values $\leq 0.05$ were considered statistically significant.

parameters, and the survivals. Owing to the long follow-up period for this patient set, PSA value was unavailable for many patients. Therefore, the analysis of correlation of ALDH1A1 expression with PSA level was not included in the study.

\section{RESULTS}

\section{Identification of a Small ALDH1A1 ${ }^{+}$Subpopulation in PCa Cell Lines with Increased Properties of Clonogenicity}

We used the ALDEFLUOR assay followed by FACS analysis to assess the presence and size of the cell population with ALDH1A1 ${ }^{+}$expression in two human PCa cell lines. The PC3 and LNCaP cell lines had a small size of the $\mathrm{ALDH}_{1 \mathrm{~A} 1}{ }^{+}$population, with $2.1 \%(2.06 \pm 1.27)$ and $2.0 \%(1.99 \pm 1.18)$, respectively (Figure 1a). However, with DEAB, an ALDEFLUOR inhibitor, cells showed $<0.03 \%$ ALDH1A1 ${ }^{+}$population.

$\mathrm{ALDH}_{1 \mathrm{~A} 1}{ }^{+} \mathrm{PC} 3$ and ALDH1A1 ${ }^{+} \mathrm{LNCaP}$ cells showed significantly a higher colony-forming efficiency (Figure $1 \mathrm{~b}$ ) by forming larger and more clones compared with ALDH1A1 ${ }^{-}$PC3 and ALDH1A1 ${ }^{-}$LNCaP cells at the end of the clonal assays. These data indicated that $\mathrm{ALDH} 1 \mathrm{A1}{ }^{+} \mathrm{PCa}$ cells could possess high proliferative capacity. As anchorageindependent growth is an approximation of tumorigenesis, and CSCs are believed to be the tumor-initiating cells, ${ }^{2}$ we further tested the ability of ALDH1A1 ${ }^{+}$and ALDH1A1 ${ }^{-}$ PCa cells to produce colonies by using soft agar assay.
$\mathrm{ALDH} 1 \mathrm{~A} 1{ }^{+} \mathrm{PC} 3$ cells generated at least three times as many colonies as ALDH1A1 ${ }^{-}$PC3 cells (Figure 1c). ALDH1A1 ${ }^{+}$ LNCaP cells also resulted in $\sim 4$ times as many colonies as did the ALDH1A1 ${ }^{-}$LNCaP cells. Furthermore, the colonies from ALDH1A1 ${ }^{+}$cells formed faster and were larger in size ( $\sim 4$ times) compared with those from ALDH1 A1 ${ }^{-}$cells (all $P<0.01)$. Although ALDH1A1 ${ }^{+}$and ALDH1A1 ${ }^{-} \mathrm{PCa}$ cells generated similar size and the number of clones in soft agar, time from plating the cells to forming clones from $\mathrm{ALDH}_{1 \mathrm{~A} 1}{ }^{+} \mathrm{PC} 3$ cancer cells was 1 week earlier $(7 \pm 2$ days) compared with ALDH1A1 ${ }^{+}$LNCaP cells. These observations indicate that $\mathrm{ALDH} 1 \mathrm{Al}^{+}{ }^{+} \mathrm{PCa}$ cells present increased in vitro clonogenicity and tumorigenicity. Moreover, ALDH1A1 ${ }^{+}$ PC3 cancer cells might have higher clonogenicity compared with ALDH1A1 ${ }^{+}$LNCaP cells.

\section{Tumor Formation of ALDH1A1 ${ }^{+}$PCa Cells In Vivo}

The gold standard in determining CSCs is whether the testing cells can preferentially initiate tumor development in animal models. ${ }^{9,22}$ We therefore implanted $\mathrm{ALDH}_{1 \mathrm{Al}}{ }^{+} \mathrm{PC}$, $\mathrm{ALDH}_{1 \mathrm{~A} 1}{ }^{-} \mathrm{PC} 3, \mathrm{ALDH}_{1 \mathrm{~A}}{ }^{+}$LNCaP, and ALDH1A1 ${ }^{-}$ LNCaP cells into $10 \mathrm{NOD} / \mathrm{SCID}$ mice, respectively. After 4 weeks, $5 \times 10^{2} \mathrm{ALDH1A1}{ }^{+} \mathrm{PC} 3$ cells yielded tumors with an average of $17 \pm 1.2 \mathrm{~mm}^{3}$ in all 10 mice, whereas the same number of ALDH1A1 ${ }^{-}$cells did not produce tumors in any mouse (Figure 2a). Furthermore, $5 \times 10^{4} \mathrm{ALDH}^{\mathrm{A} 1}{ }^{+}{ }^{+} \mathrm{PC} 3$ cells generated much larger tumors in all mice with an average of $28 \pm 1.5 \mathrm{~mm}^{3}$, whereas the same amount of ALDH1A1 ${ }^{-}$PC3 cell produced a small tumor mass $\left(8 \mathrm{~mm}^{3}\right)$ in only 1 of 10 mice (Figure 2b). Similarly, $5 \times 10^{2}$ ALDH1A1 ${ }^{+}$LNCaP cells yielded tumors with an average of $13 \pm 1.1 \mathrm{~mm}^{3}$ in all 10 mice, whereas the same dose of ALDH1A1 ${ }^{-}$cells did not generate tumors. A dose of $5 \times 10^{4}$ ALDH1A1 ${ }^{+}$LNCaP cells created tumors in all mice with an average of $25 \pm 1.3 \mathrm{~mm}^{3}$. However, the same numbers of ALDH1A1 ${ }^{-}$LNCaP cell resulted in a small tumor mass $\left(7 \mathrm{~mm}^{3}\right)$ in only 1 of 10 mice. Therefore, the ALDH1A1 ${ }^{+}$ PCa cells had at least 100 times more in vivo tumorigenicity compared with the ALDH1A1 ${ }^{-}$PCa cells, implying that the ALDH1A1 ${ }^{+}$cancer cells might be more tumorigenic than their isogenic ALDH1A1 ${ }^{-}$cancer cells.

At the dose of $5 \times 10^{2}$ cells, ALDH1A1 ${ }^{+} \mathrm{PC} 3$ and $\mathrm{ALDH}_{1 \mathrm{~A} 1}{ }^{+} \mathrm{LNCaP}_{\text {generated similar tumor incidence and }}$ size in mice. However, latency of generating xenograft tumors from ALDH1A1 ${ }^{+} \mathrm{PC} 3$ cancer cells was statistically shorter ( $8 \pm 2$ day) than that $\left(15 \pm 3\right.$ day) of $\mathrm{ALDH} \mathrm{Al}^{+}{ }^{+} \mathrm{LNCaP}$ cells $(P<0.05)$. The results indicate that ALDH1A1 ${ }^{+} \mathrm{PC} 3$ cells could have more tumorigenic property compared with ALDH1A1 ${ }^{+}$LNCaP cells.

In addition, serial transplantation experiments showed that PCa tumors developed from ALDH1A1 ${ }^{+}$cells could be regenerated for six cycles until we prepared the paper. Histopathologic examination showed a highly cellular mass with the characteristics of PCa in engrafts from ALDH $1 \mathrm{~A} 1^{+} \mathrm{PCa}$ cancer cells (Figure $2 \mathrm{~b}$ ). The observation provides functional 

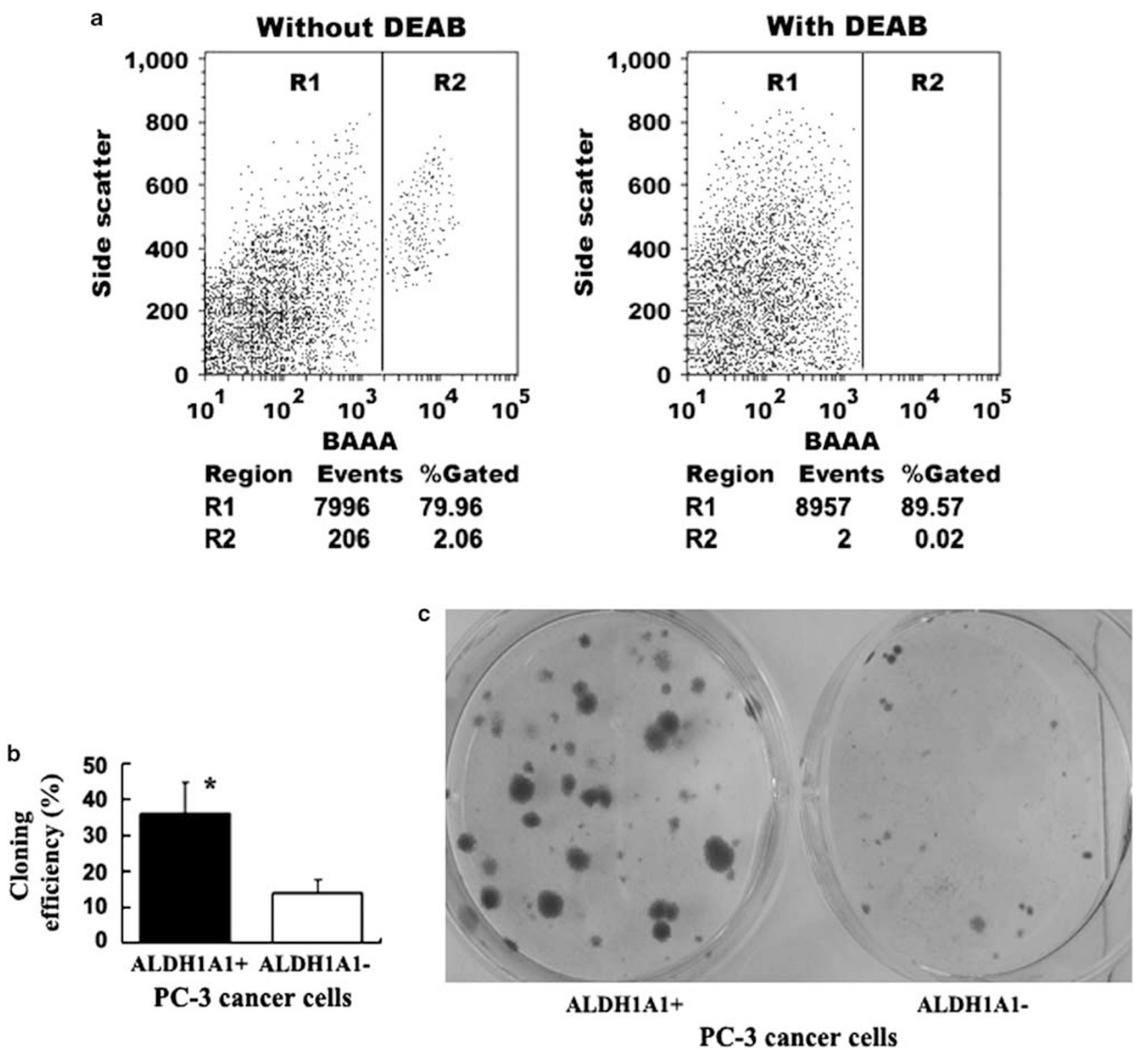

Figure $1 \mathrm{ALDH} 1 \mathrm{~A} 1{ }^{+} \mathrm{PCa}$ cells had tumor stem cell properties in vitro. (a) FACS analysis of cancer cells using the ALDEFLUOR assay. The brightly fluorescent ALDH1A1-expressing cells ( $A L D H 1 A 1^{+}$cells) were detected in the green fluorescence channel. The cells incubated with DEAB were used to establish the baseline fluorescence of these cells (R1) and define the ALDEFLUOR (ALDH1A1) ${ }^{+}$region (R2). (b) ALDH1A1 ${ }^{+} \mathrm{PCa}$ cells possessed significantly higher colonyforming efficiency compared with $\mathrm{ALDH} 1 \mathrm{~A} 1^{-} \mathrm{PCa}$ populations. $\mathrm{ALDH} 1 \mathrm{~A} 1^{+}$and $\mathrm{ALDH} 1 \mathrm{~A} 1^{-}$cells were plated in a six-well dish. At 2 weeks after plating, clones were counted and results were presented as the percentage of cloning efficiency ( $Y$ axis). Column indicates mean from three independent experiments; bars, s.e; ${ }^{*} P<0.0001$. (c) ALDH1A1 ${ }^{+}$PCa populations formatted larger and more colonies as compared with the $A L D H 1 A 1^{-}$cells by clonogenicity assays. Spheres were counted 3 weeks after plating in triplicate at 1000 per well in a six-well plate coated with soft agar. The experiments were undertaken on all PCa cell lines and repeated three times. Only the result from PC3 cell line is shown here.

evidence that $\mathrm{ALDH}_{1 \mathrm{~A} 1}{ }^{+} \mathrm{PCa}$ cells have the property of in vivo self-renewal.

To elucidate whether ALDH1A1 ${ }^{+}$PCa cells could create PCa tumors with heterogeneity in vivo, ALDEFLUOR analysis was carried out on disassociated cells of the firstgeneration tumor engrafts. The engrafted tumors from $\mathrm{ALDH}_{1 \mathrm{~A} 1}{ }^{+}$PC3 cells gave rise to $50 \%(50 \pm 3.4 \%)$ $\mathrm{ALDH}_{1 \mathrm{~A} 1}{ }^{+}$cells and $46 \%(46 \pm 2.5 \%) \mathrm{ALDH}^{-} \mathrm{Al}^{-}$cells
(Figure 2c). Furthermore, immunofluorescence analysis showed that the disaggregated cells of engrafted tumors from $\mathrm{ALDH} 1 \mathrm{Al}^{+}{ }^{+} \mathrm{LNCaP}$ cells that were initially negative

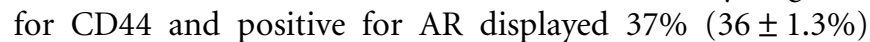
$\mathrm{CD} 44^{+}$cells and $56 \%(56 \pm 2.2 \%) \mathrm{AR}^{-}$cells, respectively (Figure 3). In addition, the engraftments from the ALDH1A1 ${ }^{+}$PC3 population that was originally positive for CD44 and negative for AR showed 29\% (28 $\pm 1.2 \%)$ CD44 

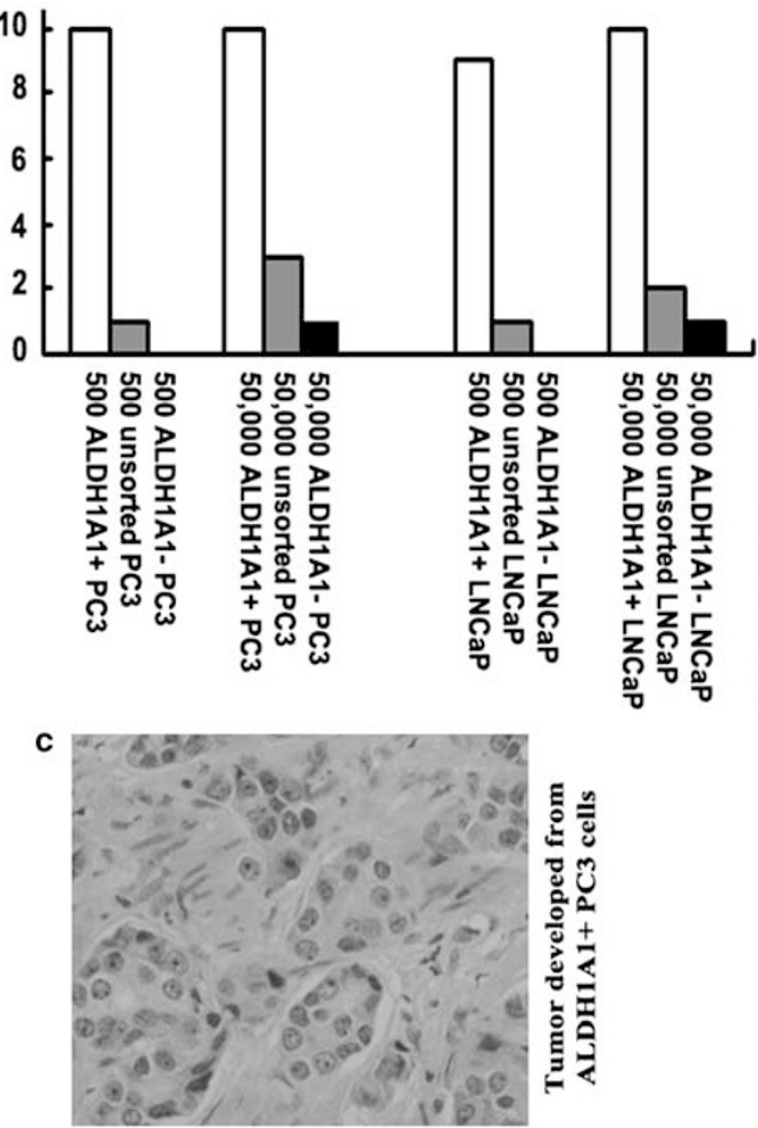

b

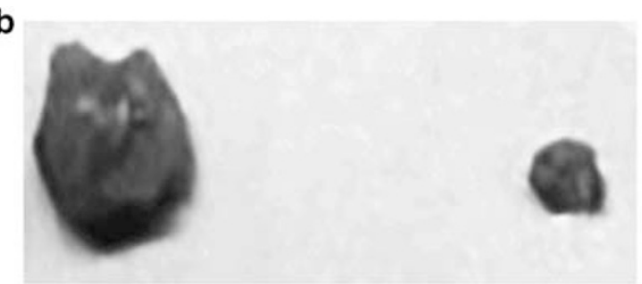

Tumor developed from ALDH1A1+ PC3 cells

\section{d}

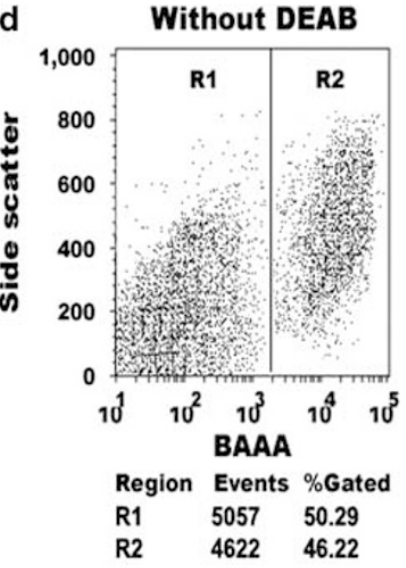

Tumor developed from ALDH1A1+ PC3 cells
Tumor developed from ALDH1A1- PC3 cells

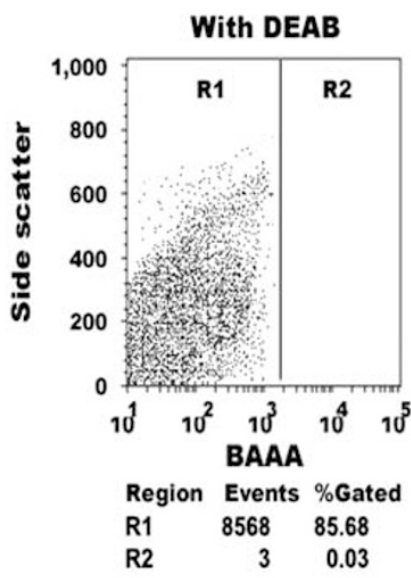

Tumor developed from ALDH1A1- PC3 cells

Figure $2 \mathrm{ALDH} 1 \mathrm{~A} 1+\mathrm{PCa}$ cells had tumor stem cell properties in vivo. (a) The tumor formation ability of ALDH1A $1^{+}$cells was greater than that of ALDH1A1 $1^{-}$cancer cells. A dose of $5 \times 10^{2}$ and $5 \times 10^{4} \mathrm{ALDH} 1 \mathrm{~A} 1^{+} \mathrm{PC}$ cells, ALDH1A1 $1^{-} \mathrm{PC}$ cells, or unsorted corresponding PC cells were injected into the dorsal prostate of $10 \mathrm{NOD} / \mathrm{SCID}$ mice, respectively, as indicted in $X$ axis. Tumor incidence refers to the number of tumors developed in the 10 mice, as shown in the $Y$ axis. After 4 weeks, $5 \times 10^{2} \mathrm{ALDH} 1 \mathrm{~A} 1^{+} \mathrm{PC} 3$ cells generated tumors in all mice, whereas the same amount of ALDH1A $1^{-} \mathrm{PC} 3$ cell did not produce tumor mass in any mouse. The dose of $5 \times 10^{4} \mathrm{ALDH} 1 \mathrm{~A} 1^{+} \mathrm{PC} 3$ cells yielded tumors in all mice, whereas the same amount of $\mathrm{ALDH} 1 \mathrm{~A} 1^{-} \mathrm{PC} 3$ cell produced a small tumor mass in only one mouse. (b) $\mathrm{ALDH} 1 \mathrm{~A} 1^{+} \mathrm{PCa}$ cells generated larger tumors compared with $\mathrm{ALDH} 1 \mathrm{~A} 1^{-}$cancer cells. A dose of $5 \times 10^{4}$ $\mathrm{ALDH} 1 \mathrm{~A} 1^{+} \mathrm{PC} 3$ cells yielded tumors with an average of $28 \pm 1.5 \mathrm{~mm}^{3}$, whereas the same dose of ALDH1A1 ${ }^{-} \mathrm{PC} 3$ cell produced a small tumor mass $\left(8 \mathrm{~mm}{ }^{3}\right)$ in only one of the mice. (c) Histopathologic examination of the engrafted tumors formed by the ALDH1A1 ${ }^{+} \mathrm{PC} 3$ cells showed a highly cellular mass with the characteristics of adenocarcinoma of prostate. (d) ALDH1A1 ${ }^{+} \mathrm{PCa}$ cells could generate PCa tumors with heterogeneity in vivo. Reanalyzing cells of the engrafts generated from the $\mathrm{ALDH} 1 \mathrm{~A} 1^{+}$and $\mathrm{ALDH} 1 \mathrm{~A} 1^{-}$cells using the ALDEFLUOR assay showed that the cells from the tumor produced by $\mathrm{ALDH} 1 \mathrm{~A} 1^{+}$ PC3 cancer cells (left panel) gave rise to $50 \% \mathrm{ALDH} \mathrm{A}^{+}{ }^{+}$population and $46 \% \mathrm{ALDH} 1 \mathrm{~A} 1^{-}$cells. However, the cells from the tumor formed by $\mathrm{ALDH} 1 \mathrm{~A} 1^{-} \mathrm{PC} 3$ cells (right panel) only produced ALDH1A1 ${ }^{-}$PC3 population.

cells and $32 \%(31 \pm 1.8 \%) \mathrm{AR}^{+}$populations. The results imply that $\mathrm{ALDH} 1 \mathrm{A1}{ }^{+} \mathrm{PCa}$ cells could produce heterogeneous populations of tumorigenic phenotypes.

Altogether, our in vivo data suggest that ALDH1A1 ${ }^{+} \mathrm{PCa}$ cells possess unique features of cancer stem-like cells, including initiation of tumorigenesis, self-renewal, and reinitiating serially transplantable tumors with multipotent differentiation potential.

\section{ALDH1A1 Expression was Sparse and Limited to the Basal Component in Normal Prostates}

As shown in Figure 4a, only a few ALDH1A1 ${ }^{+}$cells, which displayed positive cytoplasmic staining, resided in the basal cell layers of normal prostate tissues. In the adjacent sections from the same normal prostate tissues, $\mathrm{CD} 44^{+}$cells also existed in the basal component, indicating that ALDH1A1 ${ }^{+}$ and $\mathrm{CD} 44^{+}$cells were at the same locations in prostate glands (Figure 4a). However, comparison of ALDH1A1 and CD44 staining on the consecutive tissue sections showed that $\mathrm{ALDH}_{1 \mathrm{~A} 1}{ }^{+}$cells accounted for a portion of ALDH1A1 ${ }^{+}$ population, and the percentage of $\mathrm{ALDH}_{1 \mathrm{A1}}{ }^{+}$cells was statistically lower compared with that of $\mathrm{CD} 44^{+}$cells in the same basal cell layers (Figure $4 \mathrm{~b})(P<0.0001)$. Together with previous reports that the basal cell fraction includes prostate SCs ${ }^{5}$ and CD $44^{+}$cells represent normal SCs, ${ }^{5,10}$ our findings of ALDH1A1 ${ }^{+}$cells comprising a subset of $\mathrm{CD} 44^{+}$cells in the normal basal layer component might imply that the $\mathrm{ALDH}_{1 \mathrm{~A} 1}{ }^{+}$cells could be enriched in SCs of prostate. 
a

\section{ALDH1A1+ cells enriched from cultured LNCaP cells}
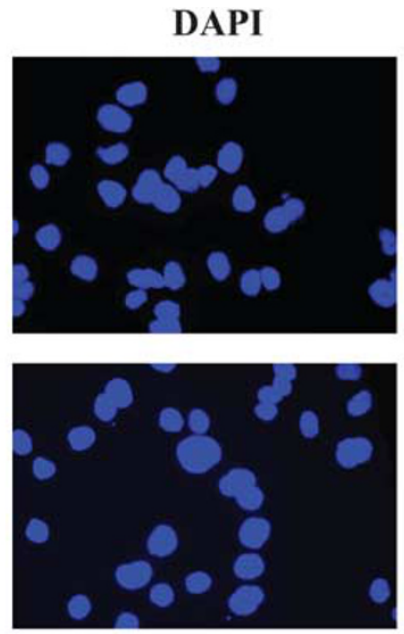

DAPI
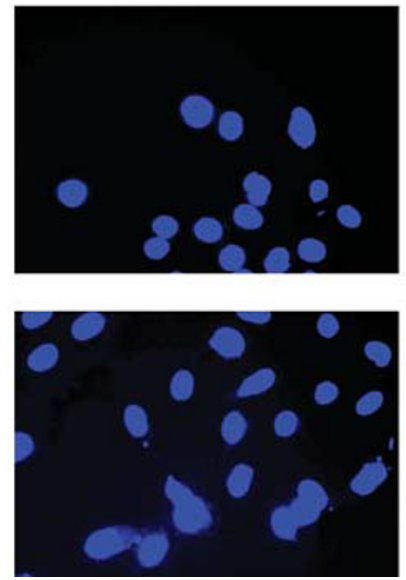

CD44
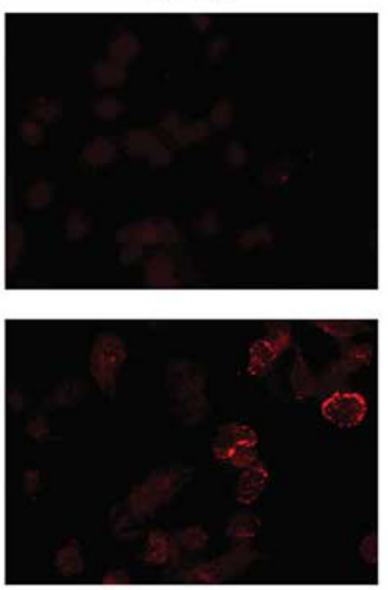

AR
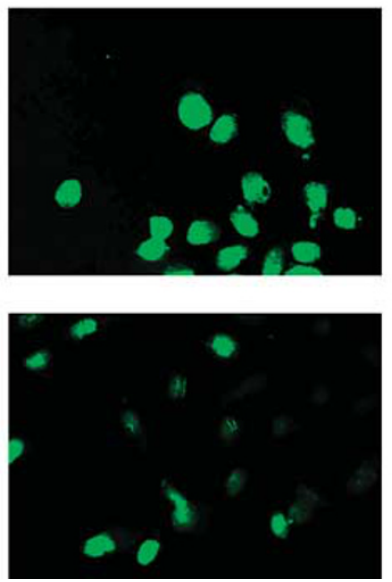
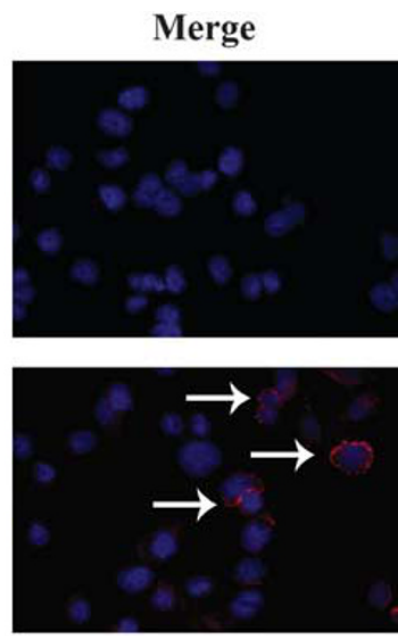

Merge
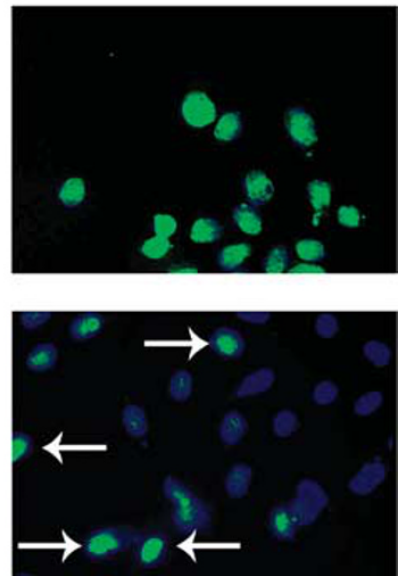

Figure $3 \mathrm{ALDH} 1 \mathrm{~A} 1{ }^{+} \mathrm{PCa}$ cells produced heterogeneous populations of tumorigenic phenotypes. (a) Immunofluorescence analysis of ALDH1A1 ${ }^{+}$cells freshly enriched from cultured LNCaP cells showed that most of the cells were negative for CD44 (weak red fluorescent staining). (b) Part of the disassociated cells of engraft developed from ALDH1A1 ${ }^{+} \mathrm{LNCaP}$ cells were positively stained for CD44, as illustrated by red fluorescence staining of the cell membrane (arrows). (c) ALDH1 $1^{+}$cells newly isolated from the same cultured LNCaP cells showed that the majority of the cells were positive for androgen receptor (AR) (green fluorescent staining of the nuclei). (d) Only fraction of the disaggregated cells of engraft produced from ALDH1A1 ${ }^{+}$LNCaP cells were positively stained for AR, as shown by green fluorescent staining of the nucleus (arrowheads). 4',6-diamidino-2-phenylindole (DAPI) was used to stain nuclei.

\section{ALDH1A1 Expression Existed in PCa Tumors with Heterogeneous Phenotypes}

ALDH1A1 expression was found in tumor tissues as illustrated by strong cytoplasm staining. Furthermore, in contrast to rare $\mathrm{ALDH}_{1} \mathrm{1}^{+}$cells in the normal basal component, a higher percentage of the ALDH1A1 ${ }^{+}$population was found in tumor tissues $(P<0.0001)$. In addition, IHC analysis of serial tumor sections showed that ALDH1A1 ${ }^{+}$cells existed not only within secretory type cancer epithelial cells that showed strong AR immunopositivity (Figure 5a) but also among neuroendocrine tumor cells that had positive chromogranin A (Figure 5b). Although the ALDH1A1 ${ }^{+}$cells only account for a subset of the $\mathrm{AR}^{+}$or chromogranin $\mathrm{A}^{+}$cancer cell populations, the observation suggests that ALDH1A1 highly expresses in a form of heterogeneity in tumor tissues, being consistent with the CSC concept, in which CSCs have a multipotent differentiation feature.

\section{Elevated ALDH1A1 Expression is Associated with a Poor Prognosis for Patients with PCa}

To assess the potential use of ALDH1A1 as a prognostic marker in PCa patients, an overall score of ALDH1A1 expression in the tissue specimens was assigned by multiplying the intensity score by the mean percentage of cells staining. ALDH1A1 expression was then stratified at three levels: absent (a specimen without any expression of ALDH1A1), present (a specimen that had $<10 \%$ of cells for ALDH1A1 expression with faint staining), and a high level (a specimen with more than $10 \%$ overall score) of ALDH1A1 expression. All normal prostate tissues had $\leq 10 \%$ of cells for ALDH1A1 expression with faint staining. Therefore, $>10 \%$ overall score was used as a cut-off, that is, a tumor specimen with more than $10 \%$ overall score was defined as one with high ALDH1A1 expression. 


\section{a}
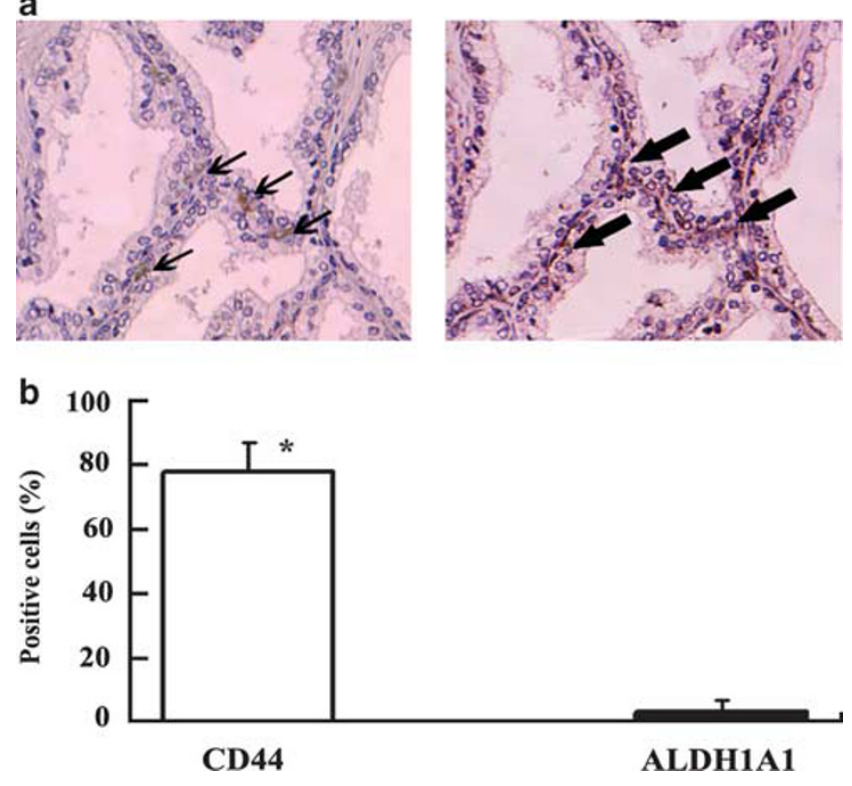

Figure 4 ALDH1A1 expression was sparse and limited to the $C D 44^{+}$basal component in normal prostates. (a) Immunohistochemical study of adjacent sections of a normal prostate tissue specimen for the expression of ALDH1A1 and CD44 showed that only a few ALDH1A $1^{+}$cells (arrows in left panel), which displayed positive cytoplasmic staining, resided in the $\mathrm{CD}_{4} 4^{+}$basal cells (arrowheads in right panel). (b) A comparison of ALDH1A1 and CD44 expressions in 18 normal prostate tissues. Bars reflect the mean percentage of positive staining cells \pm s.e. for each antibody. ${ }^{*} P<0.0001$.

On applying this criterion, high ALDH1A1 expression was found in 13 of $64(20 \%)$ PCa tumors on TMAs (Table 1), which were associated with high Gleason score $(P=0.01)$ and high pathologic stage $(P=0.01)$. Similarly, of $99 \mathrm{PCa}$ tumors with clinical follow-up information, $19(19 \%)$ tissues showed high ALDH1A1 expression (Table 2). In 99 cancers, high ALDH1A1 expression was associated with high Gleason score $(P=0.02)$ and high pathologic stage $(P=0.02)$ of the tumors. However, there was no significant association between ALDH1A1 expression and patient's age (Tables 1 and 2). These data from two independent PCa patient populations show that high ALDH1A1 expression is correlated with aggressive behavior of prostate tumorigenesis.

Kaplan-Meier survival curve analyses of 99 PCa tumors with clinical follow-up information showed that patients with high ALDH1A1 expression in their tumors had a significantly reduced overall survival rate compared with patients who had low ALDH1A1 expression $(P=0.0093)$ (Figure $5 \mathrm{c}$ ). The difference was more prominent in the PCa-specific survival data $(P=0.0017)$. Furthermore, univariate analysis showed that high ALDH1A1 expression in PCa tumors was significantly related to overall and cancer-specific survivals with hazard ratios of 1.79 (95\% CI: 1.226-2.632, $P=0.0027)$ and 1.07 (95\% CI: $1.032-1.154, P=0.0019)$, respectively.

Parameters, including age, high ALDH1A1 expression, Gleason score $(\leq 7$ versus $>8)$, pathologic stage $\left(\geq \mathrm{pT}_{3}\right.$ vs
$\mathrm{pT}_{2}$ ), were included for the Cox regression multivariate analysis. Overall and cancer-specific survivals were used as end points. High ALDH1A1 expression consistently showed a strong and independent prognostic effect on overall and cancer-specific survivals with hazard ratios of 1.73 (95\% CI: 1.163-2.527, $P=0.0066)$ and 1.05 (95\% CI: $1.028-1.107$, $P=0.0062$ ), respectively. Furthermore, Gleason score of tumors was significantly associated with the overall and cancer-specific survivals with hazard ratios of 1.34 (95\% CI: 1.010-2.193, $P=0.0016)$ and 1.11 (95\% CI: $1.021-2.215$, $P=0.0012$ ). Pathologic stage was also significantly related to the overall and cancer-specific survivals with hazard ratios of 2.23 (95\% CI: 1.713-2.899, $P=0.0029)$ and 2.10 (95\% CI: $1.771-2.736, P=0.0032)$. However, only age was shown as an independent prognostic factor for overall survival of the patients with hazard ratios of 1.62 (95\% CI: 1.052-2.632, $P=0.0458)$.

\section{DISCUSSION}

The development of specific markers to isolate and characterize CSCs of prostate tumors would greatly advance our understanding of tumor biology of prostate. A Hoechst 33342 efflux assay for collecting side population that preferentially expresses drug-efflux pumps has been used to enrich CSCs of leukemia and some solid tumors. ${ }^{2,3}$ However, the approach failed to detect a reliable side population in several commonly cultured human PCa cell lines., ${ }^{9,10}$ Recently, cell surface markers have been used to isolate CSCs from human PCa cells. For instance, CD $44^{+} / \alpha 2 \beta 1^{+} \mathrm{PCa}$ cells showed high colony-forming efficiency and capacity to differentiate into several cell types of prostate carcinoma. ${ }^{9,10}$ However, the ability of these cells to serially reinitiate transplantable tumors has not been well documented. ${ }^{10}$ Furthermore, the reliability of using the markers to identify CSCs remains controversial. ${ }^{5,10}$ For example, Collins and coworkers ${ }^{5}$ showed that a subpopulation of $\mathrm{CD} 44^{+} / \mathrm{a} 2 \mathrm{~b} 1 \mathrm{high} /$ $\mathrm{CD}_{133^{+}}$cells in clinical PCa specimens had SC characteristics in vitro. However, Pfeiffer and Schalken ${ }^{23}$ recently used CD133 to isolate CSCs from PCa cell lines. Only one (DU145) of six PCa cell lines (DU145, DuCaP, LAPC-4, 22Rv1, LNCaP, and PC-3) had a detectable CD133 ${ }^{+}$population $(0.01 \%)$. There was no difference in the ability of the $\mathrm{CD} 133^{+}, \mathrm{CD} 133^{-}$, and unselected DU145 cells to form colonies. In addition, although $\alpha 2 \beta 1^{+} \mathrm{PCa}$ cells showed higher proliferative and clonogenic potentials in vitro compared with the isogenic $\alpha 2 \beta 1^{-}$PCa cells, $\alpha 2 \beta 1^{+}$PCa cells were no more tumorigenic than the corresponding $\alpha 2 \beta 1^{-}$ cells in vivo. ${ }^{9}$ Moreover, several other cell populations have been identified that share the same marker phenotype, including circulating fibrocytes, ${ }^{22-26}$ thus limiting their application in enriching CSCs from clinical specimens. ${ }^{24}$

In this study, we successfully isolated $\mathrm{ALDH}_{1 \mathrm{A1}}{ }^{+}$cells from PCa cell lines using ALDEFLUOR assay. Several pieces of evidence support that ALDH1A1 ${ }^{+}$PCa cells could be enriched in CSCs or stem-like cancer cells. First, the in vitro 
a

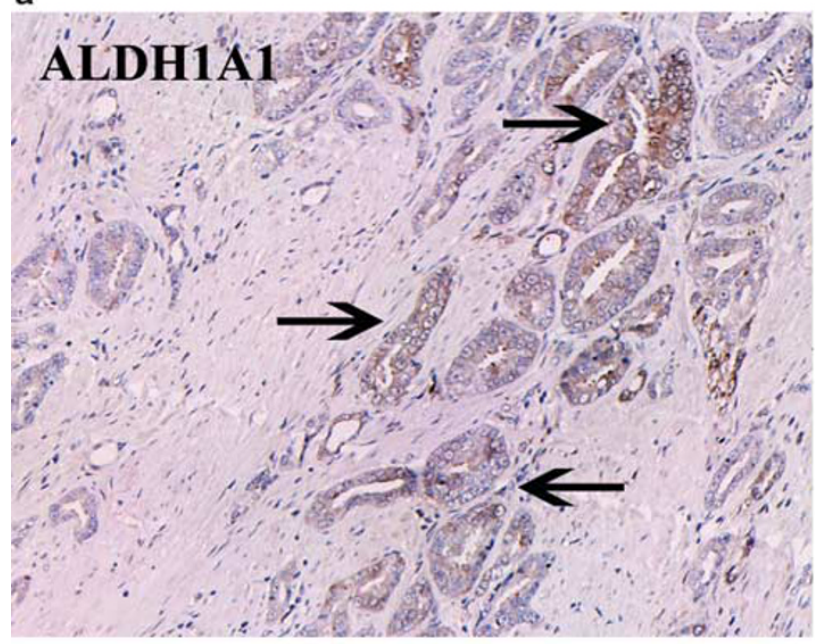

b
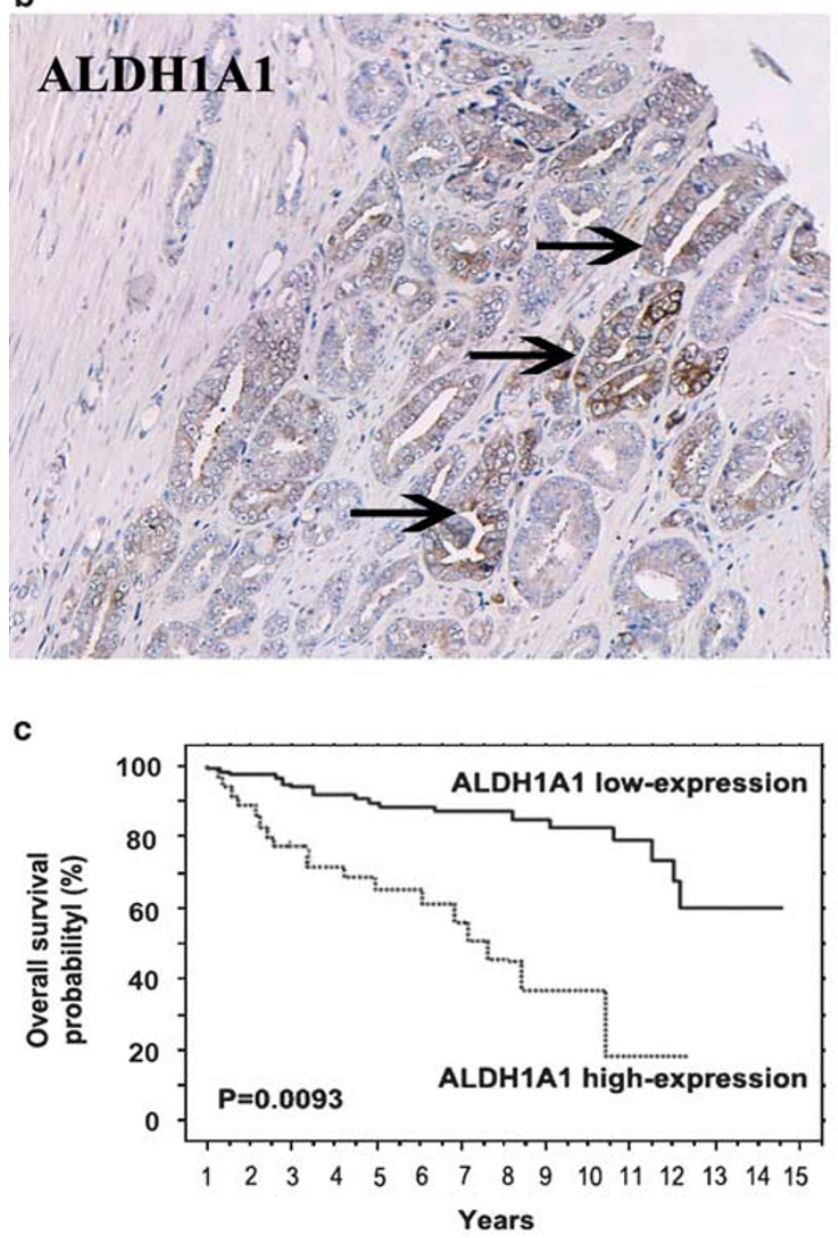
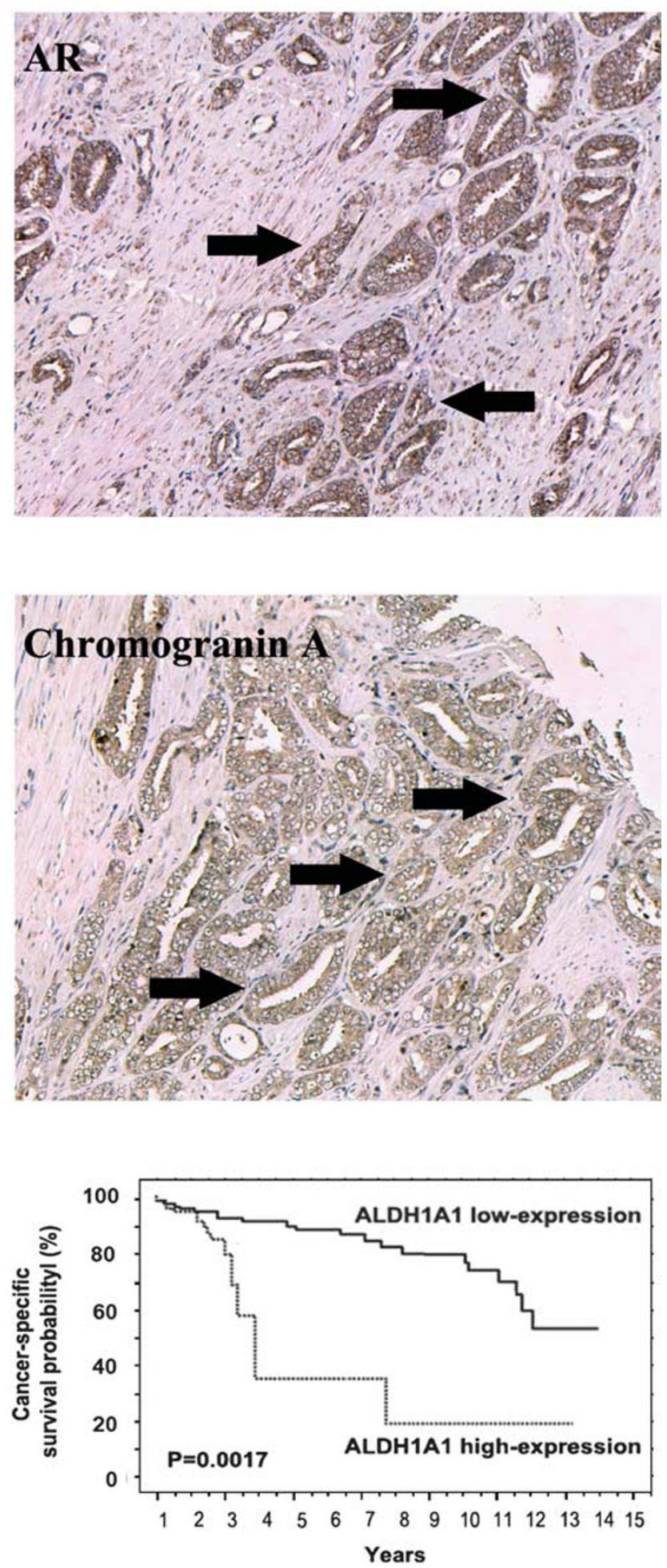

Figure 5 ALDH1A1 expression existed in PCa tumors with heterogeneous phenotypes and was associated with a poor prognosis for the patients. (a) Immunohistochemical study of adjacent sections of a PCa tumor for the expression of ALDH1A1 and AR showed that ALDH1A1 ${ }^{+}$cells (arrows in left panel) exist in a portion of secretory type cancer epithelial cells that had strong AR immunopositivity (arrowheads in right panel). (b) ALDH1A1 ${ }^{+}$cells (arrows in left panel) were present in part of neuroendocrine tumor cells that had positive chromogranin A (arrowheads in right panel). (c) Probability of overall survival (left panel) and cancer-specific survival (right panel) by levels of ALDH1A1 expression in 99 PCa patients. 
assays showed that $\mathrm{ALDH} 1 \mathrm{A1}{ }^{+} \mathrm{PCa}$ cells had higher clone formation efficiency than did ALDH1A1 ${ }^{-}$PCa cells. Moreover, ALDH1A1 ${ }^{+} \mathrm{PCa}$ cells grew in an anchorageindependent manner. Therefore, ALDH1A1 ${ }^{+}$PCa cells were highly in vitro colongenic and tumorigenic cells. Second, our in vivo experiments showed that $\mathrm{ALDH} 1 \mathrm{A1}{ }^{+} \mathrm{PCa}$ cells were at least 100 times more tumorigenic than $\mathrm{ALDH} 1 \mathrm{Al}^{-} \mathrm{PCa}$ cells. Furthermore, the engrafted tumors illustrated histopathologic patterns similar to those of the primary PCa cells, implying that the ALDH $1 \mathrm{Al}^{+}$population could resemble the characteristics of the tumor subtype and possess the capacity to self-renew. Third, the dissociated cells of the engraftments created from ALDH1A1 ${ }^{+} \mathrm{PCa}$ cells presented an average of $46 \% \mathrm{ALDH}_{1 \mathrm{A1}}{ }^{-} \mathrm{PCa}$ cells. Furthermore, the engrafted tumors from ALDH1A1 ${ }^{+}$PC3 cells that were initially negative for $\mathrm{AR}$ staining showed an average of $32 \% \mathrm{AR}^{+}$ cells. Conversely, the engrafts from the ALDH1A1 ${ }^{+} \mathrm{LNCaP}$ cancer cells that were primarily negative for CD44 staining exhibited a population of $37 \% \mathrm{CD}_{4} 4^{+}$cells. These data showed that ALDH1A1 ${ }^{+}$cells might give rise to a heterogeneous property of tumors of PCa. Fourth, importantly, ALDH1A1 ${ }^{+}$PCa cells could be serially passaged at least six times in vivo. Considering that the most crucial standard for CSCs is their ability to re-initiate successively transplantable xenografts that resemble the original tumor histology and heterogeneity, the ALDH1A1 ${ }^{+}$PCa cells could represent CSCs of prostate tumors.

Previous studies strongly suggested that the basal cell layer of adult human prostate contained SCs. ${ }^{5,10}$ For example, more than $70 \%$ of proliferating cells and molecules that are important in maintaining fundamental properties of SCs localized in this basal compartment. ${ }^{10,27}$ Furthermore, $<5 \%$ dissociated basal layer cells from adult human prostate possessed extensive proliferative capacity. ${ }^{27,28}$ In addition, under suitable culture conditions, a small population of prostatic basal cells maintained some developmental plasticity, in which cells transdifferentiated into neuronal/glial cells. ${ }^{29}$ Finally, CD44 was expressed on most basal cells and purified $\mathrm{CD}_{4}{ }^{+}$prostate epithelial cells, when co-cultured with stromal cells, produced increased amounts of PSA, probably due to the differentiation of $\mathrm{CD} 44^{+}$cells into luminal cells. ${ }^{10,30} \mathrm{CD} 4^{+}$cells were therefore believed to contain normal prostate SCs, and CD44 was considered as a marker for SCs in prostate epithelia. ${ }^{5,10}$ In this study, we show that a small ALDH1A1 ${ }^{+}$cell population is restricted to the CD44 ${ }^{+}$ basal layer cells of normal prostates, suggesting that the $\mathrm{ALDH} 1 \mathrm{Al}{ }^{+}$cells in normal prostate glands might be SCs. Investigation of whether $\mathrm{ALDH}_{1 \mathrm{A1}}{ }^{+}$normal cells can engage a multilineage repopulation of a tissue or organ, one of the most important characteristic of SC, is undertaken at our laboratory.

Although a higher percentage ALDH1A1 ${ }^{+}$cells with stronger staining signals were observed in PCa tissues compared with normal prostate tissues, only 19 and 20\% tumors showed high ALDH1A1 expression in the two sets of cancer specimens, respectively. The finding is consistent with the notion that CSCs constituted a minority of the tumor population. Interestingly, $\mathrm{ALDH} 1 \mathrm{~A}^{+}{ }^{+}$staining was present not only in secretory type cancer epithelia but also in neuroendocrine differentiated tumor cells. These data provide the evidence that ALDH1A1 expressed in a form of heterogeneity in human PCa tissues. The observation is in agreement with findings in our animal experiments, in which the disaggregated cells of the tumors generated from $\mathrm{ALDH}_{1 \mathrm{A1}}{ }^{+} \mathrm{PCa}$ cells give rise to $46 \% \mathrm{ALDH} 1 \mathrm{Al}^{-}$cells. The observation is also compatible with that the engrafted tumors from ALDH1A1 ${ }^{+} \mathrm{PC} 3$ cells originally being negative for $\mathrm{AR}$ show $32 \% \mathrm{AR}^{+}$cells, whereas the xenografts from ALDH1A1 ${ }^{+}$LNCaP cells initially being negative for CD44 display $37 \% \mathrm{CD}_{4} 4^{+}$cells. The results imply that ALDH1A1 ${ }^{+}$cancer cells might be able to differentiate into secretory and neuroendocrine epithelial cancer cells within tumor tissues. Furthermore, our observations also confirm the concept of a hierarchical organization of cancer cells existing in PCa proposed by Tang et al and others. ${ }^{9,10,31}$ On the basis of the concept, CSCs could derive from mutated CSs, and PCa cells are organized as a hierarchy with CSCs sitting at the apex and having the ability to develop (or differentiate) into a spectrum of more mature progeny. The potential of ALDH1A1 ${ }^{+} \mathrm{PCa}$ cells to 'transdifferentiate' into other cell types could help explain the biological conundrum of prostate carcinogenesis, in which although $\mathrm{PCa}$, clonal by origin, is rather heterogeneous in its cellular composition. Nevertheless, further investigation of whether and how normal ALDH1A1 ${ }^{+}$cells can transform into ALDH1A1 ${ }^{+}$ cancer populations is required.

PC3 cancer cells are androgen-independent and characterized by a marked tumorigenic phenotype. LNCaP is an androgen-dependent cell line endowed with low tumorigenic and clonogenic abilities. In this study, we find that although $\mathrm{ALDH}_{1 \mathrm{A1}}{ }^{+}$and ALDH1A1 ${ }^{-}$PCa cells generated similar size and number of clones in soft agar, time from plating the cells to forming clone from ALDH1A1 ${ }^{+}$PC3 cancer cells was 1 week earlier compared with $\mathrm{ALDH} 1 \mathrm{Al}^{+} \mathrm{LNCaP}$ cells. Furthermore, ALDH1A1 ${ }^{+} \mathrm{PC} 3$ and $\mathrm{ALDH}_{1 \mathrm{~A} 1}{ }^{+} \mathrm{LNCaP}$ cancer cells show a similar tumor incidence and end point tumor size in mice. However, latency of generating the xenograft tumors from ALDH1A1 ${ }^{+}$PC3 cancer cells is much shorter compared with that of ALDH1A1 ${ }^{+} \mathrm{LNCaP}$ cells at the same dose. The results indicate that although PC3 and LNCaP cells have similar size of ALDH1A1 ${ }^{+}$or CSC population, ALDH1A1 ${ }^{+}$PC3 cells or SC population of PC3 cells could have more clonogenic and tumorigenic property compared with those of ALDH1A1 ${ }^{+}$LNCaP cells. Our observation may support that PC3 cancer cells are more tumorigenic than LNCaP PCa cells on the basis of CSC theory. Whether ALDH1A1 is an androgen-regulated gene is currently investigated at our laboratory.

There are few markers clinically available for accurate prediction of the prognosis of PCa patients besides PSA and 
Gleason sum. ${ }^{32}$ Owing to the heterogeneous nature of PCa, it has become clear that a combination of accurate prognostic indicators is needed to improve the ability for identifying aggressive disease, so that more individualized treatments could be offered. We here show that high ALDH1A1 expression occurs in PCa samples, and is significantly associated with the Gleason score and pathologic stage. More importantly, ALDH1 expression inversely correlates with survival of the patient with PCa. A limitation of the study is that a small sample size. If the ALDH1A1 expression could be proved as a prognostic biomarker in a future large PCa population with comprehensive clinical information, the assay for analysis of ALDH1A1 might be added to the currently available prognostic factors for improving the accuracy of outcome predictions of PCa.

In summary, using in vitro and in vivo experimental systems, we show that ALDH1A1 ${ }^{+}$cancer cells are endowed with extensive proliferation and self-renewal potential, being able to generate tumors that might resemble the histopathologic characteristics and heterogeneity of the parental $\mathrm{PCa}$ cells, and therefore might have the properties of CSCs. However, further molecular biological analysis of ALDH1A1 in carcinogenesis of prostate and validating its prognostic value in a large population of PCa will be warranted.

\section{ACKNOWLEDGEMENTS}

This work was supported in part by the National Cancer Institute Grants CA113707 and CA-133956; American Cancer Society-Research Scholar Grant in Basic, Preclinical, Clinical and Epidemiology Research; a Scholar Award from

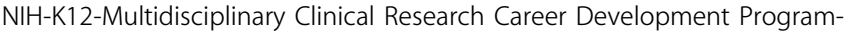
University of Maryland; and a clinical innovator award from Flight Attendant Medical Research Institute (all to FJ).

\section{DISCLOSURE/CONFLICT OF INTEREST}

The authors declare no conflict of interest.

1. Cookson MS, Aus G, Burnett AL, et al. Variation in the definition of biochemical recurrence in patients treated for localized prostate cancer: the American Urological Association Prostate Guidelines for Localized Prostate Cancer Update Panel report and recommendations for a standard in the reporting of surgical outcomes. J Urol 2007;177:540-545.

2. Reya T, Morrison SJ, Clarke MF, et al. Stem cells, cancer, and cancer stem cells. Nature 2001;414:105-111.

3. Jordan CT, Guzman ML, Noble M. Cancer stem cells. N Engl J Med 2006;355:1253-1261.

4. Horst D, Kriegl L, Engel J, et al. CD133 expression is an independent prognostic marker for low survival in colorectal cancer. Br J Cancer 2008;99:1285-1289.

5. Lang SH, Frame FM, Collins AT. Prostate cancer stem cells. J Pathol 2009;217:299-306.

6. Kelly K, Yin JJ. Prostate cancer and metastasis initiating stem cells. Cell Res 2008:18:528-537.

7. Collins AT, Habib FK, Maitland NJ, et al. Identification and isolation of human prostate epithelial stem cells based on alpha(2)beta(1)-integrin expression. J Cell Sci 2001;114:3865-3872.

8. Richardson GD, Robson CN, Lang SH, et al. CD133, a novel marker for human prostatic epithelial stem cells. J Cell Sci 2004;117: 3539-3545.

9. Patrawala L, Calhoun-Davis T, Schneider-Broussard R, et al. Hierarchical organization of prostate cancer cells in xenograft tumors: the CD44+alpha2beta1+ cell population is enriched in tumor-initiating cells. Cancer Res 2007;67:6796-6805.
10. Tang DG, Patrawala L, Calhoun T, et al. Prostate cancer stem/ progenitor cells: identification, characterization, and implications. Mol Carcinog 2007;46:1-14.

11. Yoshida A, Hsu LC, Davé V. Retinal oxidation activity and biological role of human cytosolic aldehyde dehydrogenase. Enzyme 1992;46:239-244.

12. Armstrong L, Stojkovic M, Dimmick I, et al. Phenotypic characterization of murine primitive hematopoietic progenitor cells isolated on basis of aldehyde dehydrogenase activity. Stem Cells 2004;22: 1142-1151.

13. Chute JP, Muramoto GG, Whitesides J, et al. Inhibition of aldehyde dehydrogenase and retinoid signaling induces the expansion of human hematopoietic stem cells. Proc Natl Acad Sci USA 2006;103:11707-11712.

14. Hess DA, Craft TP, Wirthlin L, et al. Widespread non-hematopoietic tissue distribution by transplanted human progenitor cells with high aldehyde dehydrogenase activity. Stem Cells 2006;26: 611-620.

15. Hess DA, Wirthlin L, Craft TP, et al. Selection based on CD133 and high aldehyde dehydrogenase activity isolates long-term reconstituting human hematopoietic stem cells. Blood 2006;107:2162-2169.

16. Pearce DJ, Taussig D, Simpson C, et al. Characterization of cells with a high aldehyde dehydrogenase activity from cord blood and acute myeloid leukemia samples. Stem Cells 2005;6:752-760.

17. Ginestier C, Hur MH, Charafe-Jauffret $\mathrm{E}$, et al. ALDH1 is a marker of normal and malignant human mammary stem cells and a predictor of poor clinical outcome. Cell Stem Cell 2007;15: $555-567$.

18. Jiang F, Qiu Q, Khanna A, et al. Aldehyde dehydrogenase 1 is a tumor stem cell-associated marker in lung cancer. Mol Cancer Res 2009;7:330-338.

19. Burger PE, Gupta R, Xiong X, et al. High ALDH activity: a novel functional marker of murine prostate stem/progenitor cells. Stem Cells 2009;27:2220-2228.

20. Palapattu GS, Wu C, Silvers CR, et al. Selective expression of CD44, a putative prostate cancer stem cell marker, in neuroendocrine tumor cells of human prostate cancer. Prostate 2009;69:787-798.

21. Sotomayor P, Godoy A, Smith GJ, et al. Oct4A is expressed by a subpopulation of prostate neuroendocrine cells. Prostate 2009;69:401-410.

22. Clarke MF, Dick JE, Dirks PB, et al. Cancer stem cells-perspectives on current status and future directions: AACR Workshop on cancer stem cells. Cancer Res 2006;66:9339-9344.

23. Pfeiffer MJ, Schalken JA. Stem cell characteristics in prostate cancer cell lines. Eur Urol 2009;19; e-pub ahead of print.

24. Croker AK, Allan AL. Cancer stem cells: implications for the progression and treatment of metastatic disease. J Cell Mol Med 2008:12:374-390.

25. Balicki D. Moving forward in human mammary stem cell biology and breast cancer prognostication using ALDH1. Cell Stem Cell 2007;15:485-487.

26. Sreerama L, Sladek NE. Class 1 and class 3 aldehyde dehydrogenase levels in the human tumor cell lines currently used by the National Cancer Institute to screen for potentially useful antitumor agents. Adv Exp Med Biol 1997;414:81-94.

27. Bhatia B, Tang S, Yang P, et al. Cell-autonomous induction of functional tumor suppressor 15-lipoxygenase 2 (15-LOX2) contributes to replicative senescence of human prostate progenitor cells. Oncogene 2005;24:3583-3595.

28. Hudson $\mathrm{DL}, \mathrm{O}^{\prime}$ Hare $\mathrm{M}$, Watt FM, et al. Proliferative heterogeneity in the human prostate: evidence for epithelial stem cells. Lab Invest 2000;80:1243-1250.

29. Raff M. Adult stem cell plasticity: fact or artifact? Annu Rev Cell Dev Biol 2003;19:1-22.

30. Liu AY, True LD, LaTray L, et al. Cell-cell interaction in prostate gene regulation and cytodifferentiation. Proc Natl Acad Sci USA 1997;94:10705-10710.

31. Gu G, Yuan J, Wills M, et al. Prostate cancer cells with stem cell characteristics reconstitute the original human tumor in vivo. Cancer Res 2007;67:4807-4815.

32. Cohen BL, Gomez P, Omori Y, et al. Cyclooxygenase-2 (COX-2) expression is an independent predictor of prostate cancer recurrence. Int J Cancer 2006;119:1082-1087. 